\title{
IDADE DO METAMORFISMO DE ALTO GRAU NO COMPLEXO ANÁPOLIS-ITAUÇU, GOIÁS, DETERMINADA PELO MÉTODO Sm-Nd
}

\author{
DANDELLE PIUZANA FISCHEL, MÁRCIO MARTINS PIMENTEL* \& REINHARDT ADOLFO FUCK
}

\begin{abstract}
THE AGE OF HIGH GRADE METAMORPHISM IN THE ANÁPOLIS-ITAUCU COMPLEX, GOIÁS, DETERMINED BY THE Sm-Nd METHOD The Anápolis-Itaucu Complex, in Goiás, is a high-grade terrane including granites, mafic-ultramafic bodies as well as sediments, ali metamorphosed in granulite facies. One sample of a granitoid body metamorphosed in granulite facies, containing sillimanite and garnet, was investigated using the Sm-Nd method. The mineral isochron, including analyses of garnet, monazite and biotite concentrates, indicates an age of $633 \pm 28 \mathrm{Ma}$ and $8 \mathrm{Nd}(\mathrm{T})$ of ca. -7.0. This is interpreted as the best estimate so far of the age of the high-grade metamorphism in the Anápolis-Itauçu Complex and represents the first typically Brasiliano $(600 \pm 30 \mathrm{Ma})$ age for high-grade rocks in the Brasília Belt.
\end{abstract}

Keywords: granulites, Brasília Belt, Brasiliano

RESUMO No Complexo Anápolis-Itauçu, em Goiás, estão expostos granulitos ortoderi vados de composição granítica e básica/ultrabásica, granulitos aluminosos para derivados e corpos graníticos intrusivos de caráter predominantemente peraluminoso. Uma amostra de granitóide metamorfisado na fácies granulito, contendo silirhanita e granada, foi investigada pelo método Sm-Nd. A isócrona mineral incluindo análises em concentrados de granada, monazita e biotita, revelou uma idade de $633 \pm 28$ Mae ENd(T) de ca. -7.0. Essa idade é interpretada como indicadora do evento de alto grau metamórfico registrado nessa rocha e representa a primeira idade tipicamente Brasiliana $(600 \pm 30 \mathrm{Ma})$ de rochas de alto grau na Faixa Brasília.

Palavras-chave: granulitos, Faixa Brasilia, Brasiliano

INTRODUÇÃO Trabalhos recentes de geocronologia têm evidenciado um importante evento metamórfico de alto grau com idade de ca. $780 \mathrm{Ma}$ em rochas dos três grandes maciços máfico-ultramáficos de Goiás (Barro Alto, Niquelândia e Cana Brava) da Faixa Brasília (Ferreira Filho et al 1994, Suita et al. 1994, Correia et al. 1997).

Outra importante área de exposição de rochas de alto grau na Faixa Brasília situa-se na região centro-sul de Goiás (Fig. 1) e é conhecida sob a denominação de Complexo Anápolis-Itauçu, a qual compreende uma faixa alongada segundo NW com ca. de $200 \mathrm{~km}$ de comprimento. Essas rochas têm sido tradicionalmente interpretadas como o embasamento siálico antigo da Faixa Brasília, muito embora não existam, até o momento, dados geocronológicos conclusivos. Neste trabalho reportamos os primeiros dados $\mathrm{Sm}-\mathrm{Nd}$ de granitóides de alto grau expostos nas proximidades de Anápolis.

CONTEXTO GEOLÓGICO REGIONAL E AMOSTRA ANALISADA A área investigada localiza-se na porção centro-sul de Goiás (Figura 1), é parte do Complexo Anápolis-Itaucu e está inserida na chamada zona interna da Faixa Brasília (Fuck et al. 1994).

O complexo é constituído por granulitos básicos, metapiroxenitos, hiperstênio granulitos félsicos e metagranitos, aos quais se associam granulitos aluminosos ricos em sillimanita e granada, possivelmente derivados de sedimentos. Também são conhecidos granulitos aluminosos que representam antigos corpos graníticos. As rochas granulíticas do Complexo Anápolis-Itauçu estão limitadas pelas coberturas dobradas do Grupo Araxá, sendo as relações de contato marcadas por zonas de cisalhamento (Araújo 1994).
O afloramento do granitóide aqui nvestigado (amostra ANA-1) situa-se na saída sudoeste de Anápolis para Goiânia, na BR 153, próximo à localidade de Marinápolis. Trata-se de um granitóide fortemente foliado, cinza claro, com textura porfiroclástica dada por cristais de granada de até $6 \mathrm{~cm}$ de diâmetro, e composto por plagioclásio, feldspato potássico, quartzo, granada, biotita e silimanita. Monazita, zircão e opacos são acessórios. A paragênese de alto grau metamórfico não apresenta evidências de re-equilíbrio posterior em condições de $\mathrm{P}$ e T mais baixas.

RESULTADOS E CONCLUSÃO As análises isotópicas (Tabela 1) resultaram em uma isócrona mineral que indica a idade de $633 \pm 28$ Ma e $\varepsilon_{\mathrm{Nd}}(\mathrm{T})$ de ca. -7.0 (Fig. 1). Essa é interpretada como a melhor estimativa, até o momento, da idade do evento metamórfico de alto grau na região, e representa a idade mais jovem já registrada para o metamorfismo de alto grau na Faixa Brasília. Essa idade é semelhante às obtidas pelos métodos $\mathrm{Sm}-\mathrm{Nd}$ em granada e U-Pb em titanita de outras áreas da Faixa Brasília (Pimentel et al. 1991, 1998).

$\mathrm{O}$ resultado obtido representa o primeiro registro de metamorfismo de alto grau de idade tipicamente Brasiliana $(600 \pm 30 \mathrm{Ma})$ na Faixa Brasília, o que sugere a existência de dois eventos de formação de granulitos na faixa, sendo o mais antigo de $780 \mathrm{Ma}$ (Ferreira Filho et al 1994, Suita et al 1994, Correia et al 1997) determinado em rochas máficas granulitizadas dos complexos máfico-ultramáficos de Barro Alto, Niquelândia e Cana Brava.

Tabela l-Dados isotópicos Sm-Nd.

\begin{tabular}{|c|c|c|c|c|c|}
\hline Amostra & $\begin{array}{c}S m \\
(p p m)\end{array}$ & $\begin{array}{c}N d \\
(p p m)\end{array}$ & ${ }^{19 /} S m /^{144} \overline{N d}$ & $\begin{array}{c}{ }^{143} N d f^{144} N d^{*} \\
(2 S E)\end{array}$ & $\begin{array}{l}T_{D M} \\
(G a)\end{array}$ \\
\hline ANA-1 RT (1) & 15,79 & 137,7 & 0,069 & $0,511779(05)$ & 1,32 \\
\hline ANA-1 monazita & 9.320 & 80.72 & 0,070 & $0,511756(05)$ & - \\
\hline ANA-1 granada & 9,584 & 8,117 & 0,714 & $0,514429(05)$ & - \\
\hline ANA-1 biotita & 4,020 & 28,31 & 0,085 & $0,511808(10)$ & - \\
\hline
\end{tabular}




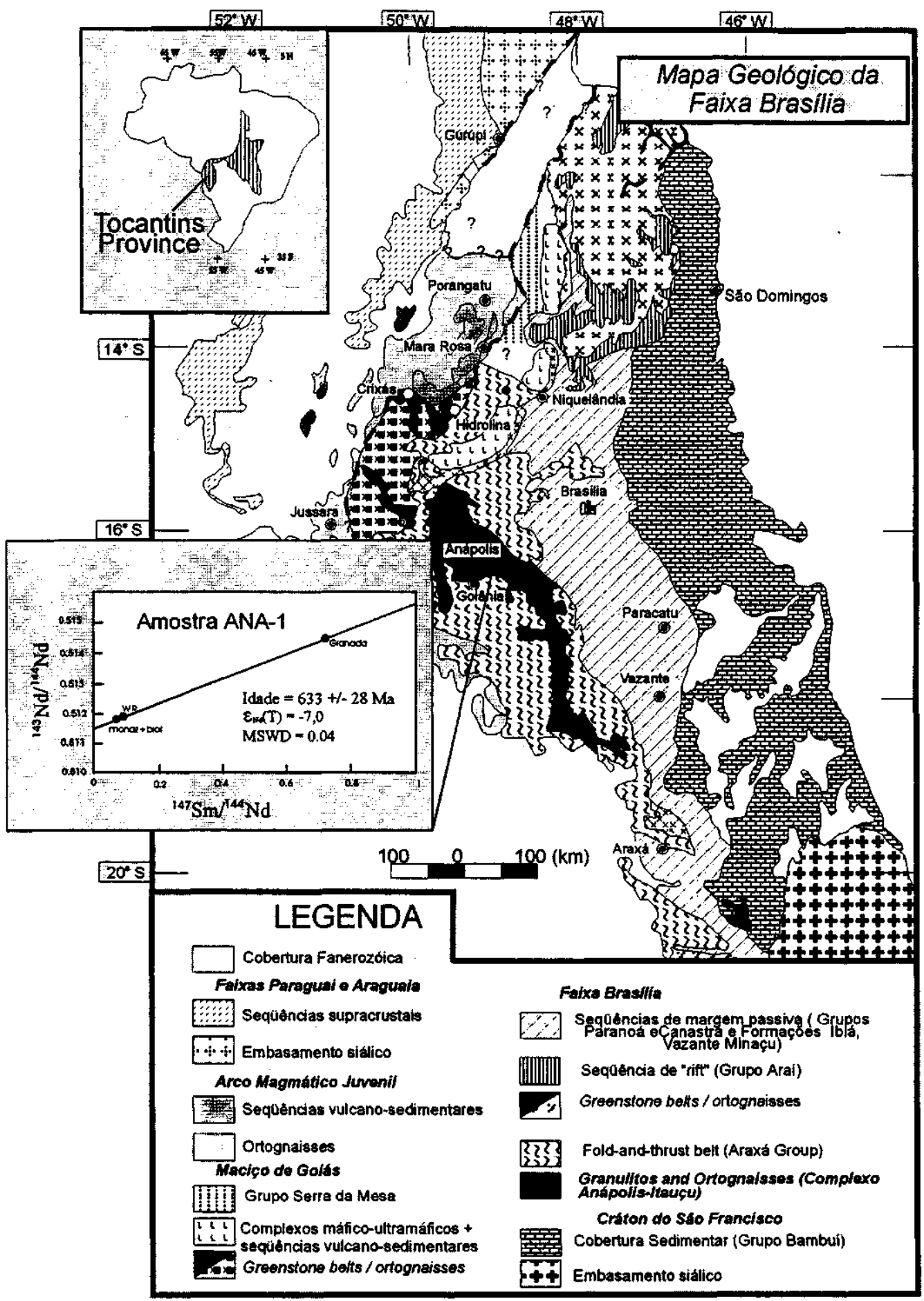

Figura l - Esboço geotectônico da Faixa Brasília, localização da área de estudo e isócrona mineral Sm-Nd para amostra ANA-1

\section{Referências}

Araújo, V.A. 1994. Programa de levantamentos geológicos básicos do Brasil. Nerópolis -Folha SE.22-X-B-I. Estado de Goiás. Escala 1:100.000. Goiânia, DNPM/CPRM, 120p.

Correia,C.T.; Tassinari.C.C.G.; Lambert.D.D.; Kinny, P.; Girardi.V.A. V. 1997b. U-Pb (SHRIMP), Sm-Nd and Re-Os systematics of the Cana Brava, Niquelândia and Barro Alto layered intrusions in central Brazil, and constraints on the tectonic cvolution. In: South-Am. Symp. Isotope Geology - SSAGI, 1., ExtendedAbstracts..., IG-USP, Campos do Jordão, pp.88-89.

Ferreira Filho.C.F.; Kamo.S.; Fuck, R.A.; Krogh, T.E.; Naldrett, A. J. 1994. Zircon and rutile $\mathrm{U}-\mathrm{Pb}$ geochronology of the Niquelândia layered mafic and ultramafic intrusion, Brazil: constraints for the timing of magmatism and high grade metamorphism. Precamb. Res., 68:241-255.

Fuck, R.A.; Pimentel, M.M.; Silva, L.J.H.D. 1994. Compartimentaçâo tectônica da porção oriental da Província Tocantins. In: Cong. Brasil. Geologia, 38., Boletim de Resumos Expand., v.1... SBG, Camboriú, 1994, p.215-216.
Pimentel, M.M.; HEAMAN.L., FUCK.R.A. -1991-U-Pb zircon and sphene geochronology of late Proterozoic volcanic are rock units from southwestern Goiás, Central Brazil. Jour. South American Earth Sei, 4:329-339.

PIMENTEL. M.M.; FUCK, R.A.; JUNGES, S. 1998. New Sm-Nd isotopic constraints for the age of metamorphic events in the Neoproterozoic Brasilia Belt, central Brazil. 14 International Conference on Basement Tectonics. Ouro Preto, MG. pp. 50-52.

SUITA.M.T.F., KAMO.S.L., KROGH.T.E., FYFE,W.S., HARTMANN.L.A. 1994. U-Pb ages from the high-grade Barro Alto mafic-ultramafic complex (Goiás, Central Brazil): middle Proterozoic continental mafic magmatism and Upper Proterozoic continental collision. In: Inter. Confer. on Geochr. Cosmochr. and Isot. Geol., 8., Abstracts... Berkeley, USGS, p.309.

Manuscrito NB-18 Recebido em 01 de novembro de 1998 Revisã o dos autores em 20 de novembro de 1998 Revisã 0 aceita em 21 de novembro de 1998 